Daimon. Revista Internacional de Filosofía, no 74 (Mayo-Agosto) 2018, 71-88

ISSN: 1130-0507 (papel) y 1989-4651 (electrónico)

http://dx.doi.org/10.6018/daimon/266491

\title{
Herbert Marcuse: "El final de la utopía” en el siglo XXI
}

\author{
Herbert Marcuse: "The End of the Utopia" in the $21^{\text {st }}$ Century
}

\author{
$M^{a}$ CARMEN LÓPEZ SÁENZ*
}

\begin{abstract}
Resumen: Este trabajo estudia el concepto de "utopía" en la obra de Herbert Marcuse con objeto de comprender su malinterpretada y descontextualizada proclamación del final de la utopía en 1967. Comenzamos, para ello, diferenciando la utopía de la ideología con la ayuda de Mannheim y Ricoeur y situando la utopía marcusiana en el contexto de la Escuela de Frankfurt y de la utopía concreta (Bloch). Desde su temprana crítica a Mannheim, Marcuse se mostrará como filósofo dispuesto a restaurar las dimensiones reprimidas de la racionalidad y el libre juego de las facultades conducente a una nueva antropología. Valoraremos la crítica habermasiana a la utopía y concluiremos presentando algunas cristalizaciones de la utopía marcusiana en el siglo XXI.

Palabras clave: Utopía, Teoría Crítica, Ideología, Imaginación, Estética.
\end{abstract}

\begin{abstract}
This paper studies the concept of "utopia" in the work of Herbert Marcuse in order to understand his misconstrued and decontextualized proclamation of the end of the utopia in 1967. I will start with the distinction between utopia and ideology with the help of Mannheim and Ricoeur, and with the contextualization of Marcusian utopia in the Frankfurt School as well as in the concrete utopia (Bloch). From his early criticism of Mannheim, Marcuse is shown as a philosopher willing to restore the repressed dimensions of rationality as well as the free play of the faculties leading to a new anthropology. I value the Habermasian critique of utopia and I conclude presenting some crystallizations of the Marcusian utopia in the XXI century.

Key words: Utopia, Critical Theory, Ideology, Imagination, Aesthetics.
\end{abstract}

\section{1. ¿Es la utopía otra ideología?}

Frente al concepto tradicional de la utopía como una sociedad fantaseada, K. Mannheim (1893-1947), forjador del concepto contemporáneo de la utopía, en Ideología y utopía (1929) la define como "incongruente" con el estado de cosas actual y como trascendencia del mismo (Mannheim, 1987, 178). Contrapone la utopía a la ideología en razón de que, aunque ambas

Recibido: 26/08/2016. Aceptado: 02/02/2017.

* Catedrática del Departamento de Filosofía, UNED (Madrid), clopez@fsof.uned.es Líneas principales de investigación: Fenomenología de la existencia, sociofenomenología, Teoría Crítica, fenomenología y feminismo, hermenéutica fenomenológica y estética contemporánea. Entre sus publicaciones recientes destacan LÓPEZ SÁENZ, M ${ }^{\mathrm{a}}$ C. (2018), La hermenéutica filosófica de H-G. Gadamer en busca de la verdad. Madrid: Dykinson. LÓPEZ SÁENZ, Mª C. (2018): "H. Marcuse: Filosofía crítica contra el totalitarismo de la unidimensionalidad" en Sánchez-Meca, D. Herrera, R. Villacañas, J.L. (eds.) (2018): Totalitarismo. La resistencia filosófica (15 estudios de pensamiento político contemporáneo). Madrid: Tecnos, pp. 109-130.

Este trabajo se ha desarrollado en el marco del proyecto de investigación financiado por el MINECO, "El carácter trascendental de la hermenéutica fenomenológica y la posibilidad de la antropología filosófica". FFI2015-63794-P. 
son distorsiones de la realidad, la ideología mantiene la situación social existente, mientras que la utopía tiende a transformarla de manera radical. Otro rasgo distintivo es que la decadencia de la ideología solo constituye una crisis para determinada clase social, mientras que la desaparición de la utopía lleva al inmovilismo y a la cosificación del ser humano (Ib., 229-230). La utopía posee, por tanto, valor antropológico.

Ricoeur (1913-2005), en cambio, las considera complementarias para interpretar la realidad. El pensamiento utópico no solo presta a la ideología un género semántico, una narratividad, sino que los modelos ideales de sociedad son puntos de referencia para las diversas ideologías políticas. Siguiendo a Ricoeur, la ideología presenta una acepción positiva y otra negativa y deformadora; lo mismo sucede con la utopía, la cual es positiva cuando hace referencia a algo no existente que permite escrutar reflexivamente lo posible; en cambio, la utopía negativa es la que pretende fabricar un mundo nuevo empleando la violencia. ${ }^{1}$

En la línea de C. Geertz (1926-2006), Ricoeur entiende el aspecto positivo de la ideología como factor cultural necesario para la integración social. En efecto, las autorrepresentaciones compartidas crean vínculos, memoria social y marcos interpretativos para entender y clasificar acciones, acontecimientos, textos, etc. En su versión negativa, en cambio, la ideología ejerce el dominio; lo hace, generalmente, sin que tengamos conciencia explícita de ello; en otras palabras, pensamos desde ella más que sobre ella. Su detección y desenmascaramiento son necesarios para el desarrollo de esa otra concepción de la utopía favorecedora de la vida en común.

Frente al carácter dinámico o generativo de la utopía y de la ideología positivas ricoeurianas que estarían en la base de la motivación de los individuos y de la praxis social, el marxismo ha denostado la ideología por considerarla enmascaradora de la verdadera realidad social, la cual está determinada por la infraestructura. Desde la perspectiva del filósofo francés, el error de esta aproximación radica en su identificación de la ciencia con el verdadero conocimiento y en su ceguera ante la constitución simbólica de la realidad social. Solo abriendo los ojos a ésta, se puede entender, sin embargo, que la realidad sea susceptible de deformación ideológica.

Ricoeur no contrapone la ideología a la ciencia, como hace el marxismo, sino que la relaciona con la praxis, frente a la techné. Explica cómo opera a través de la materialidad de la acción simbólica, la cual sirve de mediación entre los intereses y las formas de representación de la imaginación. Esto no significa que ignore el carácter crítico concreto de la utopía, sino que, a diferencia de Habermas (1929-) y en consonancia con Gadamer, sabe que la ideología no es completamente accesible a la reflexión crítica; es decir, aunque intentemos analizarla, nuestros juicios e interpretaciones nunca serán los del observador externo e imparcial, puesto que pertenecen a la realidad social que pretendemos conocer. En otras palabras, la razón crítica nunca puede llegar a ser reflexión total, porque la distancia exigida por la crítica es tan solo un momento de la pertenencia y esta también es obra de la razón común. Así es como Ricoeur se distancia de la ideología crítica de la Escuela de Frankfurt.

Como esta última, nosotros entendemos la utopía no como un sueño imaginario, sino como crítica de las insuficiencias de la situación establecida y superación (Aufhebung) de la misma. Así hay que juzgar el negativismo de estos filósofos, como utopía cuyo sentido

1 La polaridad de cada término se atribuye a la imaginación cultural (Ricoeur, 1994, pp. 45-46). 
principal es liberarse de esa lógica infernal que reduce las ideas a aporías de lo existente: "Lo mejor, hacia lo que tiende la razón utópica es lo que se presenta como ausente" (Perlini, 1976: 38). Esta razón utópica se ha orientado por El principio de esperanza (1938-47) de Bloch (1885-1977), especialmente en lo referente al paso de la sociedad ya liberada a su concreción política, o en lo que su autor denominaba "utopía concreta" y Marcuse recobra entendiéndola principalmente como trascendencia de la dominación actual: "Entonces la utopía concreta (y su monstruosa negación en la sociedad existente) se convierte en el hilo conductor del análisis empírico. Este revela que la superación [Aufhebung] de la utopía es ya una posibilidad real, existente" (Marcuse, 2014, 396).

Bloch diría que incluso la ideología contiene un residuo utópico que puede emplearse críticamente. Análogamente, si la esperanza surge de la crítica, no será vana; se fundará en condiciones concretas.

\section{Herbert Marcuse (1898-1979)}

\section{a) Critica a la interpretación sociológica de Mannheim}

El mismo año en el que Mannheim publicaba Ideología y utopía, salía a la luz la reseña de Marcuse, "Sobre la problemática de la verdad del método sociológico. Ideología y utopía de Karl Mannheim". ${ }^{2}$ En ella, valora el interés de Mannheim por el ser histórico, aplaudiendo que no lo considere algo último, sino apuntando más allá de sí, a una verdad. La fase descriptiva de su historicidad ni se dirige a ella ni puede fundamentar una interpretación. Por otro lado, la interpretación no puede ser meramente sociológica, pues la sociología "desvincula el pensamiento del ser y hace abstracción del "momento intencional de todo acontecer" (Marcuse, 2011, 45). La intencionalidad en la que piensa es la motivación que permite comprender las acciones humanas. La echa en falta en Mannheim, quien, a pesar de haber puesto en relación la teoría con la verdad, piensa que lo verdadero en la historia es una conciencia o un pensamiento. Marcuse lo entiende también como "una situación concreta y su orden de vida" (Ib., 49). Así, por ejemplo, de la historicidad y de la mera facticidad del capitalismo no se sigue su equivalencia histórica con otros sistemas; es preciso afrontar su verdad y, en general, la verdad de lo histórico para no caer ni en el relativismo del "todo vale" ni en el determinismo. Su tratamiento no consiste ni en absolutizar la historia ni la verdad, sino en comprender las realizaciones fácticas sobre la base de estructuras fundamentales: aquellas son modificaciones históricas de estas "que son realizadas de manera diversa en cada orden de vida" (Ib., 53). Verdad y falsedad residirían en la relación de las realizaciones fácticas con tales estructuras fundamentales: un orden de vida será verdadero si las satisface, falso si las encubre. Marcuse parece pensar en los existenciarios heideggerianos aplicados ahora a las estructuras marxistas de la realidad, e incluso en las estructuras o esencias a las que llega Husserl (1859-1938) variando imaginativamente los hechos. El fundador de la fenomenología tampoco se limita a describirlas, sino que investiga su verdad, es decir, la relación de lo fáctico con las estructuras, de la realidad con la razón.

2 Die Gesellschaft, 6 (1929), pp. 356-369 (Marcuse, 2011, 37-54). 
Marcuse se opone asimismo al juicio de Mannheim sobre el marxismo como ideología que refleja la situación histórica de una clase social dada. El filósofo berlinés defiende la validez de un marxismo fenomenológico que describe las estructuras de la vida común y proporciona criterios para la praxis. Para ello, hace suya la antropología del joven Marx y adapta su crítica de la alienación a los sutiles métodos tanto del capitalismo avanzado como del socialismo soviético, tan alejado del socialismo marcusiano, en el que no hay determinismo, ni reduccionismo económico, sino que lo material y lo cultural, los individuos y la sociedad están interrelacionados.

Ciertamente, la Teoría Crítica extrae sus metas y verdades del estudio de las tendencias presentes en el proceso social. Sin embargo, no teme que el nuevo orden sea denunciado como una utopía, porque esta pone de manifiesto que la verdad no puede realizarse en el orden social establecido; por eso lo trasciende, porque es más racional. Esto es lo que caracteriza a la filosofía de la Escuela de Frankfurt frente a otras corrientes contemporáneas: "La obstinación de adherirse a la verdad contra toda apariencia ha cedido su lugar a la rareza y al oportunismo descarado en la filosofía contemporánea. La Teoría Crítica preserva la obstinación como una genuina cualidad del pensamiento filosófico" (Marcuse, 2009, 106).

Su obstinación en la utopía como afán crítico y emancipatorio, le permitió a Marcuse superar el pesimismo de la Escuela e incluso, como declara su hijo, Peter, la dialéctica negativa de Adorno, inscribiéndose "en el proyecto de reconstruir la razón y plantear alternativas utópicas a la sociedad existente". 3 Tal reformulación pasa por la rehabilitación de la imaginación.

\section{b) La imaginación. Facultad de la utopía}

Marcuse concede una gran importancia a la imaginación o fantasía en la crítica y renovación de la razón. La conceptualiza como la facultad de la utopía, porque convierte lo posible y razonable en real, liberándolo de su carácter represivo. La imaginación, además, se niega a aceptar el orden fáctico, es el Gran Rechazo: la protesta contra la represión innecesaria y la defensa de posibilidades reales de liberación que han sido relegadas a la tierra de nadie de la utopía por el principio del rendimiento impuesto por el capitalismo avanzado al principio de realidad.

Mientras que el positivismo renuncia a la imaginación y a la utopía, la filosofía marcusiana está orientada al futuro y, para transformar el presente se sirve de la imaginación: "Sin fantasía todo conocimiento filosófico queda atado al presente o al pasado, separado del futuro, que es lo único que vincula a la filosofía con la historia real de la humanidad" (Marcuse, 1968, 94). El futuro es capaz de atraer y movilizar las fuerzas del presente arrancándolas de la sujeción al pasado, de la tendencia a la repetición a expensas de la creación. Para que la filosofía adopte como objetivos del presente lo que aún no lo es, necesita fantasía. Siguiendo a Freud, Marcuse afirma que esta "sigue hablando el lenguaje del principio de placer, de la liberación de la represión, del deseo y la gratificación no inhibidos; pero la realidad actúa de acuerdo con las leyes de la razón, que ya no están relacionadas con el lenguaje de los sueños" (Marcuse 1981, 139). Solo la imaginación es capaz de representar

3 Marcuse, P. "Foreword", en: Marcuse, 1998, XIV. 
la reconciliación del individuo con la totalidad, de la felicidad con la razón. Aunque esta armonía haya sido aplazada por el principio de rendimiento, la fantasía insiste en que puede y debe llegar a ser real y, en efecto, las verdades de la imaginación toman forma en el universo subjetivo-objetivo del arte (López Sáenz, 2000, 31-38) y en su promesa de gratificación. La imaginación y la utopía conforman, por consiguiente, una razón renovada y un pensamiento autónomo que denuncia los abusos de la racionalidad abstracta que se ha vuelto irracional.

En síntesis, la utopía, tal y como Marcuse y la Escuela de Frankfurt la entienden, se compone de dos elementos: la crítica de lo existente y, desde ella, el esbozo de lo que debería existir. Que no pueda determinarse su proyecto futuro no implica que la utopía de la Teoría Crítica sea abstracta, sino que, como decíamos, es concreta hasta el punto de poder demostrar que es realizable en el estado actual de las fuerzas productivas desarrolladas por el ser humano.

\section{c) El final de la utopía}

En 1967, Marcuse imparte una serie de conferencias en la Universidad Libre de Berlín, que se plasmarán en el libro El final de la utopía. Como los otros Frankfurtianos, apela al negativismo de la Teoría Crítica de la sociedad, que se identifica con el marxismo más crítico de la alienación. Con esa negación de lo fáctico comienza la utopía, y continúa con la denuncia de la represión de las posibilidades liberadoras. El negativismo marcusiano se halla a medio camino del pesimismo y del optimismo, pero no es sinónimo de neutralidad ni de pasivismo. El filósofo es consciente de que, en términos hedonistas, siempre es más rentable consolidar el sistema que rechazarlo; lo que ocurre es que la felicidad a la que aspira no es individual, sino colectiva, y el rechazo que postula obedece a que «la libertad solo es posible como realización de aquello que aún hoy se llama "utopía” (Marcuse, 1968, 13).

A diferencia de Freud, advierte que la idea de una civilización no represiva ya ha dejado de ser utópica, dado que las condiciones técnicas de la época la hacen perfectamente realizable. Existe ya la posibilidad real de una transformación en el ámbito material que conduzca a nuevas formas de vida. Por eso asegura que ha llegado el fin de la utopía:

[...] esto es, la refutación de las ideas y las teorías que han utilizado la utopía como denuncia de posibilidades histórico-sociales [...] las nuevas posibilidades de una sociedad humana y de su mundo circundante no son ya imaginables como continuación de las viejas, no se pueden representar en el mismo continuo histórico, sino que presuponen una ruptura precisamente con el continuo histórico, presuponen la diferencia cualitativa entre una sociedad libre y las actuales sociedades no libres, la diferencia que, según Marx, hace de toda la historia transcurrida la prehistoria de la humanidad (Marcuse, 1968, 7).

Dicha diferencia requiere un cambio cualitativo, porque hasta el presente las necesidades eran un fiel reflejo de la sobrerrepresión de los instintos necesaria para constituir la civilización del trabajo. En los años 60, el desarrollo alcanzado ya no exige dicha represión y, por ello, lo que antes parecía utópico podría materializarse, pero no lo hace por culpa de la organización social y la dominación. 
La utopía que ha finalizado es, pues, aquélla que se presuponía imposible, la utopía extrahistórica, la que literalmente se aceptaba como $u$-topos, es decir, como irrealizable. Existe en cambio, un concepto histórico de utopía, una utopía que, aunque no se ha realizado, puede encontrar un lugar en el tiempo. Es u-topía ahora, pero es posible. Se ha iniciado dentro de lo real, pero trascendiendo, como decíamos, sus manifestaciones fácticas. Marcuse defiende este concepto histórico de "utopía". Asegura que hay factores objetivos (posibilidades brindadas por la ciencia, la técnica y el desarrollo de la producción) y subjetivos (rebelión de la nueva sensibilidad) que permiten ya la transformación, aunque esta no se produce. Por eso dice que hay que volver a hacer desde la ciencia hasta la utopía el camino del socialismo descrito por F. Engels (1820-1895) como camino desde la utopía hasta la ciencia (Ib., 8), es decir, los conceptos tienen que dejar de orientarse por la facticidad y hacerlo por la virtualidad.

La utopía histórica es y no es todavía. Incita, por ello, a una actitud de búsqueda incesante, idéntica a la actitud de la filosofía. Tiene la función de violentar los límites del orden existente. De ahí su necesidad de forzar a la realidad a que aproveche todas las posibilidades que contiene. Marcuse la defiende en 1967 por su relevancia para la liberación y por su viabilidad. Cuando se le preguntó cómo se podrían distinguir las utopías aparentes de las auténticas, respondió diciendo que era posible eliminar el poder basado en la explotación, pero no "la autoridad racional" (Ib., pp. 44-45), es decir, la necesaria y reconocida (por ejemplo, la de un profesor o un médico). Ahora bien, debido a la tergiversación de la razón, ese reconocimiento no siempre es inmediato. La restauración del mismo exigiría distinguir las verdaderas de las falsas necesidades y, para ello, se necesitaría una nueva antropología.

\section{d) Una nueva antropología}

Marcuse habla de "El fin de la utopía", porque ha concluido la prehistoria de la humanidad y su historia clama por una nueva antropología que saque a los seres humanos de su unidimensionalidad y fomente la necesidad vital de libertad como el único reconocimiento que puede propulsar el cambio cualitativo de la existencia:

En el sentido de esas necesidades vitales, la nueva antropología implica también la génesis de una nueva moral como heredera y negación de la moral judeo-cristiana, la cual ha determinado hasta ahora, en gran parte, la historia de la civilización oriental. La continuidad de las necesidades desarrolladas y satisfechas en una sociedad represiva es en medida considerable lo que reproduce constantemente esa sociedad represiva en los individuos mismos. Los individuos reproducen en sus propias necesidades la sociedad represiva, incluso a través de la revolución, y precisamente esa continuidad de las necesidades represivas es lo que ha impedido hasta ahora el salto de la cantidad a la cualidad de una sociedad libre (Ib., 12).

El concepto histórico de utopía defendido por Marcuse requiere, pues, un cambio cualitativo. Ahora prefiere este término al de "revolución" que, en ocasiones, se ha limitado a sustituir un sistema de dominación por otro. El cambio cualitativo radical, por el contrario, 
no será impuesto, sino reconocido por una nueva antropología. Esta será el motor de la transmutación propuesta en Eros y Civilización, que podría sintetizarse como convergencia de la técnica con el arte, del trabajo con el libre juego de todas las facultades humanas. Esta meta solo será alcanzada por un ser humano nuevo, poseedor de una conciencia crítica y auto-crítica. Podríamos preguntarnos, no obstante, si esta conciencia es premisa de la liberación o resultado de ella. No hay que olvidar que, como el hombre nuevo, se forma en el interior de lo existente (Habermas, 1986, 134), no en la mera voluntad; sin embargo, cuando reflexionamos sobre lo existente, nos damos cuenta de que "la liberación es la más realista, la más concreta de todas las posibilidades históricas y, al mismo tiempo, la más reprimida, efectiva y racionalmente, la posibilidad más abstracta y remota" (Marcuse, 2001, 99).

El fin de la nueva antropología tiene, por tanto, un sentido trágico, pues se afirma como una posibilidad real y como condición necesaria de la liberación, pero, al mismo tiempo es sistemáticamente desviado y reprimido. Esta nueva antropología no es una propuesta utópica de retroceso a un paraíso perdido en los inicios del capitalismo, sino un camino que solo tiene ida y cuya meta nunca puede considerarse alcanzada. Por ello, al igual que Merleau-Ponty, Marcuse es partidario de una transformación permanente sin síntesis, un cambio radical hacia el interior y hacia el exterior que produzca una transvaloración y una nueva dirección del progreso científico hacia objetivos de pacificación no de reproducción del sistema productivo a costa de la aniquilación:

"Pacificación", "libre desarrollo de las necesidades y facultades humanas", son conceptos que pueden ser definidos empíricamente en términos de los recursos y capacidades intelectuales y materiales disponibles, y de su uso sistemático para atenuar la lucha por la existencia. Ésta es la base objetiva de la racionalidad histórica (Marcuse, 1985b, 249).

Esa racionalidad que se hace en la historia no surge automáticamente del desarrollo de las fuerzas productivas como predecía el socialismo científico. Marcuse piensa en un socialismo cualitativamente diferente de los comunismos que han tenido lugar, en un socialismo "como utopía concreta que se ha convertido en una posibilidad real" (Marcuse, 2005, 179), y que se toma en serio la diferencia cualitativa, cuyo detonante será una nueva sensibilidad, unida a la racionalidad mediada por la imaginación. Esa diferencia es, como hemos visto, la liberación, y se plasmará en nuevos fines de la producción, contextualizados en un amplio proyecto de solidaridad y de cooperación, basado en la nueva sensibilidad:

El marxismo ha de asumir el riesgo de definir la libertad de tal modo que se haga consciente y se perciba como algo que en ningún lugar subsiste aún ni ha subsistido. Y precisamente porque las posibilidades llamadas utópicas no son en absoluto utópicas, sino negación histórico-social determinada de lo existente, la forma de la consciencia de esas posibilidades y la toma de consciencia de las fuerzas que las impiden y las niegan exigen de nosotros una oposición muy realista, muy pragmática. Una oposición libre de toda ilusión, pero también de todo derrotismo, el cual traiciona ya por su mera existencia las posibilidades de la libertad en beneficio de lo existente (Marcuse, 1968, 18). 
Solo existe la posibilidad de elegir entre la racionalización del statu quo y el cambio cualitativo. Pero para elegir lo verdadero y mantenerse en él es preciso transformar las voluntades, aspirar a una racionalidad gratificante ligada a una nueva sensibilidad.

\section{e) Negativismo no es pesimismo. Líneas alternativas}

Solo un nuevo ser humano podrá escapar a la integración en el capitalismo avanzado y acometer el cambio cualitativo, no ya por su pobreza material, sino porque habrá tomado conciencia de la miseria moral, de la irracionalidad reinante y, en suma, de la deshumanización general. No será la escasez la que lo inspire, sino la repulsión ante el despilfarro y la superabundancia de la sociedad de consumo fomentada por el capitalismo avanzado. Esto demuestra que la nueva antropología que el filósofo berlinés reclama no es compleja ni quimérica. A pesar de ello, se le ha acusado de carecer de alternativas concretas. Su concepción de la utopía es, como hemos visto, coherente con ello, pero el negativismo no es sinónimo de neutralismo, sino crítica exacerbada de lo fáctico. Es en esa crítica donde hay que buscar lo positivo. Así pues, la negación es ya una alternativa concreta (Marcuse, 1968, 142-143). Un ejemplo de ello es la negación marcusiana del proletariado como clase revolucionaria. En su época, el trabajo intelectual estaba sustituyendo al manual y esta es la razón por la cual, en ocasiones, Marcuse concreta sus esperanzas en los estudiantes e intelectuales.

Esa confianza se traduce en la importancia de la educación para la autorreflexión crítica, o sea, para que los seres humanos quieran la libertad y no se limiten a desear que no se pongan peor las cosas. Piensa en una educación transformadora y política, en una contraeducación desenmascaradora de los deseos y las falsas necesidades creadas que nos han determinado al consumo compulsivo y a la unidimensionalidad. Rechaza la educación que trata a los seres humanos como capital y como consumidores de los productos del sistema sin cuestionar su verdad. Cabría, no obstante, preguntarse quién educará a los educadores. Tal vez podrían hacerlo los intelectuales, dado que se encuentran en el origen de esa contradicción entre la capacidad liberadora de la ciencia y su uso autoritario que impide la concreción de la utopía. Puntualiza, no obstante, que su labor no es adoctrinadora, sino "una función preparatoria decisiva" (Marcuse, 1985a, 113). Con esta propuesta, Marcuse supera el prejuicio revolucionario contra los intelectuales. Él mismo se implicó en los movimientos estudiantiles de los años 60, tan críticos del capitalismo como del socialismo real. Los intelectuales no deben aislarse, pues esto impediría su acercamiento a una sociedad libre; han de volver a la caverna, no tanto para ilustrar como para guiar hacia la luz que arroja el negativismo. Sin embargo, debemos insistir en que, desde su óptica, los intelectuales solo son la propedéutica de una nueva educación teórico-práctica e integral ${ }^{4}$ cuyo fin no es politizar el sistema educativo, pues ya lo está, sino poner en práctica una educación política, en su sentido más originario, es decir una educación para lo común que no enseñe solo destrezas y habilidades, sino que cambie a los sujetos y transmute la raíz de los valores de la dominación que, siguiendo al filósofo berlinés, está en "una dimensión por debajo de la base material" (Ib., 105).

4 "Hoy la educación debe comprender el espíritu y el cuerpo, la razón y la imaginación, las necesidades intelectuales $y$ el instinto" (Marcuse, 1985a, 114). 
Dado que incluso las bases instintivas se encuentran subyugadas y la psicología profunda ha sucumbido a la política, es necesaria una contra-política educativa que sea capaz "de preparar el fondo espiritual para una jerarquía cualitativamente diferente de valores y de poder" (Ib., 75). Son condiciones de esta educación liberadora que no esté financiada por ningún patrocinador particular y que no siga la tendencia conductista que cercena la autonomía individual y sustituye la experiencia crítica por la de los hechos brutos de brutales consecuencias.

Contra la imposición de la racionalidad instrumental que reduce todo a simple medio, la educación por la que apuesta Marcuse pone en relación todas las facultades humanas, priorizando, de la misma manera que Schiller, la educación estética. El arte complementa la educación general del nuevo individuo, ya que su objetivo no es implantar una nueva cultura opuesta a la del despilfarro y a la cultura mosaico, sino transformar las relaciones humanas que se han convertido en valores de cambio. El pensador berlinés no obvía la contradicción que supone pensar dentro de la sociedad existente una educación para otra sociedad futura; más bien, se da cuenta de la urgencia de resolverla "si ha de darse el progreso" (Ib., 89).

El último Marcuse sigue denunciando las nuevas formas de administración y control del sujeto, mientras busca focos de resistencia que promuevan esa dialéctica de la liberación que consta al menos de dos premisas: la necesidad vital de abolir los sistemas de servidumbre establecidos y el compromiso con valores cualitativamente diferentes, los únicos capaces de definir una existencia humana libre (Ib., 97-98). El sujeto de la transformación cualitativa no es una clase social, sino diversos movimientos y grupos, como los estudiantes de la época, los intelectuales o los marginados que están fuera del sistema y, por ello, podrían destruirlo. Nosotros nos preguntamos si estos son realmente un potencial revolucionario o solo aspiran a una mayor integración. Únicamente si poseen formación y tienen voluntad de outsiders pueden integrar movimientos alternativos.

En suma, para una educación crítica como la promovida por Marcuse, la racionalidad deja de ser formal y estratégica para abrirse a dimensiones que se le sustrajeron (emociones, sentimientos, sensibilidad e incluso sensualidad) fueron manipuladas sin restricción. Debido a ello, la racionalidad crítica es vinculada a la filosofía, a la sociología y a la historia.

\section{f) Filosofía, verdad y utopía}

Ni en el siglo XX ni en el XXI hay una clase social cuyos intereses representen la crítica y la negatividad; la voluntad de verdad ha de seguir siendo asumida por la filosofía. Su función es la misma que la de la Teoría Crítica: reconocer las potencialidades de la liberación en las dimensiones de la racionalidad tachadas de "irracionales" por la razón instrumental. Este reconocimiento recuerda las posibilidades utópicas que son, sin embargo, posibilidades históricas reales. Consecuentemente, en el pensamiento crítico, la razón ya no es una herramienta para elaborar la realidad dada, sino que se revela como fuerza de transformación que extrae de los hechos sus posibilidades reprimidas.

La nueva racionalidad marcusiana apela a la filosofía para recuperar la intención crítica de las categorías neutralizadas por la ciencia. Marcuse establece una serie de criterios por los que esa "racionalidad más alta" puede acometer el proyecto trascendente de mejorar la 
civilización, sin eludir juicios de valor: "creo que el mismo concepto de Razón se origina en este juicio de valor, y que el concepto de verdad no puede separarse del valor de la Razón" (Marcuse, 1985b, 248-9).

La razón marcusiana no es meramente un nivel de conocimiento, ni siquiera una facultad, sino la integración de todas. La filosofía crítica refleja esa razón capaz de mostrar la realidad como aquello que es; también puede sacar a la luz aquello que la realidad impide que sea; en definitiva, es capaz de comprender la realidad sin mutilarla y de distinguir la verdadera de la falsa conciencia de la misma. Esta filosofía es dialéctica entre teoría y praxis, además de una filosofía de la emancipación que es el resorte del deber-ser, incluyendo el de lo que nunca debería ser abolido aunque no se haya realizado.

Recordemos que, para Marcuse, la filosofía es siempre actividad; no puede limitarse a describir lo que es, no es puro positivismo, sino revelación de la verdad, y esta tiene carácter existencial. La actividad filosófica es un modo de la existencia humana y esta se encuentra a cada instante en una situación histórica determinada. La razón de la filosofía debe reconocer lo irracional en la realidad establecida y ejercer la negación histórica. Esta negación tiene bases empíricas porque es un proyecto histórico dentro y más allá de otro ya realizado. Su verdad no está determinada por su mera realización y por el éxito social, sino por las posibilidades de pacificación de la existencia que ofrece (Marcuse, 1985b, 252). La razón solo puede ser correlato de esa verdad y cumplir esta función como racionalidad postecnológica en la que la técnica sirva a la paz y constituya el arte de la vida.

Confía en la posibilidad de una "tecnología de la liberación" (Marcuse, 1985a, 108) en la que converjan la técnica y el arte, el trabajo y el juego, el reino de la necesidad y el de la libertad, una tecnología que no esté sometida a la lógica de la rentabilidad capitalista. Solo una sociedad que desarrolle estas posibilidades liberadoras estará en condiciones de perseguir esta meta y, entonces, la razón se aproximará al arte. Pero, el arte es una bella promesa de cambio que por si sola no puede cumplir. A pesar de ello, la experiencia estética siempre subvierte la experiencia y, aunque por sí misma no pacifique la existencia, puede crear la necesidad de la paz. Ella misma es una necesidad inalienable para todos los seres humanos.

Ya justificamos por qué la imaginación es la facultad de la utopía; digamos ahora que la estética es una "utopía antropológica" 5 y un modo de concretar la utopía, pues consiste en la libertad de representar lo no existente y de "nombrar lo que de otra manera es innombrable" (Marcuse, 1985, 276).

La unión del arte y la filosofía reflejaría la fusión de la imaginación con la razón; ambas estarían entonces en condiciones de asumir el negativismo de la utopía, o sea, de juzgar el presente sin rendirse a los hechos, orientadas a la verdad. Esta resulta de la conciliación entre razón y realidad, pero tal conciliación no es inmediata. Verdad es aquello que no es y que debería ser, aquello que supera lo que es para reafirmarlo como lo que es en verdad. La fidelidad a la utopía se explica entonces como un continuo ejercicio crítico a través del cual la realidad es proyectada para que coincida con la realización de la razón.

Cuando la verdad no es realizable dentro del orden existente, se la tacha de utópica. Marcuse piensa que es precisamente tal trascendencia la que la hace verdadera. El com-

5 Así reza el título de la obra clásica de Jiménez (1983). 
ponente utópico (esa adhesión a la verdad aun en contra de toda evidencia) ha sido, según Marcuse, el único elemento progresista de la filosofía en ocasiones. Consideramos que en su propia filosofía esta fidelidad a la verdad que trasciende lo dado ha sido conservada como cualidad auténtica del pensar. Si el objetivo de la filosofía marcusiana es la búsqueda de la verdad más allá de la evidencia empírica, la razón (ampliada y transformada por la nueva sensibilidad) es la categoría fundamental del pensamiento filosófico, la única que lo vincula al destino del ser humano.

Siguiendo al berlinés, la filosofía debe conservar el significado pleno de conceptos como la Belleza, la Justicia, la Felicidad; estos términos transcienden sus realizaciones particulares y es misión de la filosofía comprender las posibilidades realizadas de los mismos a la vez que las que son soslayadas. Los conceptos filosóficos son esencialmente críticos, y es su carácter abstracto el que les permite dar cuenta de lo concreto así como permanecen fuera de la integración. Esto es lo que hace posible pensar en medio de las lacras de la realidad, detectar y sacar a la luz las fisuras del orden establecido.

Ahora bien, la realización de la razón -como decíamos- es una tarea teórico-práctica. Para Marcuse, "razón” significa organización de la vida según la libre decisión del sujeto. Esto quiere decir que la razón debe crear una organización social en la que los individuos puedan regular su vida de acuerdo con sus verdaderas necesidades. Cuando este desarrollo no se produce, la teoría debe adoptar una postura crítica; si la verdad se torna irrealizable dentro del orden existente, la crítica toma frente a este la forma de la utopía.

\section{La crítica habermasiada a la utopía}

J. Habermas representa a la segunda generación de la Escuela de Frankfurt. En relación con el tema que aquí nos ocupa, considera que el peligro de la utopía negativa de sus predecesores es su caída en el pesimismo, el quietismo y la reclusión en la contemplación teórica de otro futuro, con la consiguiente pérdida de la anhelada unidad teoría-praxis. Para evitarlo, él contrarresta el dualismo que todavía subyacía a la primera generación -principalmente la dicotomía entre racionalidad instrumental y racionalidad liberadora- con su introducción de la racionalidad comunicativa y su diagnóstico de que dicha racionalidad práctica e intersubjetiva orienta al mundo de la vida, que ha sido colonizado parcialmente por la Modernidad a la vez que se ha ido democratizando.

No suscribe la estetización marcusiana de la utopía, ni el sentido de telos que adquieren en ella la naturaleza y la historia. En cambio, nosotros pensamos que es preciso reivindicarlo como un horizonte vital, no solo como ideal comunicativo contrafáctico. La base antropológica de la teoría de Marcuse necesita, desde la perspectiva habermasiana, más justificación si no quiere limitarse a ser un desarrollo meramente individual, y aspira a fundamentar las premisas normativas y prácticas de la Teoría Crítica. Marcuse le respondería que hoy la noción utópica no solo es ya un concepto histórico, "sino también un imperativo histórico que tiene que servir para contrarrestar la petrificación del socialismo bajo nuevas formas de dominación" (Marcuse, 2001, 138). La universalidad de las normas se asienta en la radicalidad de la propuesta marcusiana de una razón ampliada a las pulsiones, la sensibilidad y la imaginación que no sea impuesta, sino reeducada y reconocida libremente por los individuos. 
Antes de su muerte, en la sala de cuidados intensivos de un hospital, Marcuse le desveló a Habermas que por fin había comprendido cuál era la raíz de los juicios de valor: la compasión, el sentimiento del sufrimiento con los otros (Habermas, 1983, 296).

¿Es la compasión una empatía (Einfuihlung) con el dolor ajeno, sea este físico o no? El dolor propio es una experiencia interna; solo sus síntomas son descriptibles o exteriorizables, pero el dolor ajeno no se aprehende por experiencia inmediata, sino por empatía. Marcuse concluía así que el padecer juntos es correlativo al actuar colectivamente, de mismo modo que el placer no se comprende sin el dolor (López Sáenz, 2006). De ninguna manera estaba claudicando ante el sufrimiento. Nunca equiparó la filosofía ni con el ser-para-la muerte ni con el sacrificio, pues ambos, en su opinión, traicionan la utopía, ya que convierten un hecho biológico en una esencia existencial y se rinden a ella.

Habermas asegura con él que asistimos al final de una determinada utopía, pero solo para alumbrar otras nuevas. No estamos presenciando la irrupción de una época postmoderna sin utopía. La utopía que ha concluido es la de la sociedad del trabajo, la del socialismo utópico que ha dejado de serlo, porque el desarrollo de las fuerzas productivas es tal que el trabajo alienado y la penuria podrían ya eliminarse. De esa utopía del trabajo surgió el estado Social que, en nuestros días, ha perdido, no obstante, la posibilidad de proyectar una vida colectivamente mejor. El capitalismo actual no puede vivir sin él, pero tampoco si el denominado "estado del bienestar" se sigue extendiendo. El creciente número de parados es otro hecho que pone en cuestión la vieja utopía del trabajo. Su solución no es solo un mayor número de prestaciones, pues así no se supera la gestión administrativa de nuestra existencia.

Una nueva división de poderes aseguraría, desde la perspectiva habermasiana, el intercambio entre el sistema y el mundo de la vida, es decir, el mundo de la integración social, de la acción orientada al entendimiento y de la solidaridad por la que se mantiene y reproduce. El mundo de la vida tendría que afirmarse contra los otros dos recursos: dinero y poder administrativos (Habermas, 1984, 543-544).

Poco queda de la solidaridad obrera que alimentó la utopía de la sociedad del trabajo, incluso del objetivo último de la liberación concebida como trabajo no alienado. El desarrollo técnico y la globalización económica parecen haberlo superado. Frente a este panorama, como es sabido, Habermas ha propuesto una tipología de las acciones y un intercambio entre los aspectos sistémicos y mundano-vitales que nos permita vislumbrar la utopía de la comunicación libre de dominio, capaz de dar sentido a la historia y fusionar lo histórico con lo utópico: "Los acentos utópicos se desplazan desde el concepto de trabajo al concepto de comunicación. Y hablo nada más de acentos, porque este cambio de paradigma de la sociedad del trabajo a la sociedad de la comunicación cambia también el tipo de conexión con la tradición utópica (Ib., 545).

A nuestro modo de ver, hoy que los medios de comunicación de masas dirigen y vehiculan las informaciones, cuando las encuestas no predicen, sino que determinan, hoy que la televisión tan pronto construye una noticia como le dice adiós e Internet acerca a todos los habitantes del globo a las mismas ofertas creándoles falsas expectativas, la utopía de la comunicación habermasiana se diluye en la red de redes. Como él mismo ha afirmado, la web es incapaz de suplir a la esfera pública que atendía a las cuestiones políticamente importantes. Al mare magnum de ruidos digitales le falta la fuerza inclusiva de una esfera pública que seleccione lo realmente importante (Habermas, 2014). 
Z. Bauman (1925-2017) coincide con él: la globalización ha vacíado de contenido a la esfera pública que, finalmente, se ha concentrado en su privatización. El triunfo del mercado des-regularizado demuestra el fracaso del Estado del bienestar, que ya solo ofrece al individuo seguridad policial (Bauman, 2008, 13). La solución que Bauman ofrece consiste en reconstruir el espacio del ágora para asegurar la constante relación entre lo privado y lo público $(2002,129)$. Marcuse, en cambio, pensaba que incluso la individuación de su época era falsa, porque era impuesta por una sociedad undimensional y porque realmente no podía haber vida privada sin vida pública.

\section{Lo utópico del "fin de la utopía" en el siglo XXI}

Esperamos haber clarificado el concepto no convencional de utopía defendido por Marcuse, así como su desmitificación de lo que usualmente se designa como utópico o especulativo tan solo porque no se quiere que se realice, ni siquiera en un momento en el que podría tomar concreción. Hemos visto que su anunciado fin de la utopía no equivalía al fin de la historia como tal, sino al de la historia unidimensional precedente. Su propuesta consiste en salir de esa horizontalidad clausurada y trabajar en favor de una historia vertical, cualitativamente distinta.

El "fin de la utopía" significaba, pues, su realización. Eso ya era viable en el siglo de Marcuse en el que las condiciones históricas hacían posible lo que Bloch llamaba una "utopía concreta". Hoy como en 1967, la grandeza y la miseria del momento consisten en que por primera vez en la historia el hombre puede alcanzar sus utopías gracias al poder tecnológico, pero este poder es empleado contra dicha posibilidad. Se diría que la razón ha perdido la razón.

Por ello, la postmodernidad ha renunciado a la utopía, al sujeto, a la verdad e incluso a la razón ... El relativismo abandona su búsqueda y así no solo se contradice afirmando desde un lugar absoluto que no hay verdad o sentido, sino que condena nuestros actos a la opacidad. Nuestra convicción es que en la era global y multicultural, solo se llegará a una transmutación de la política y de las instituciones en la dirección reclamada por la ciudadanía con utopía, comenzando con la utopía del diálogo tan raramente realizado.

Dado que las posibilidades llamadas "utópicas" son la negación histórico-social determinada de lo existente, su eliminación conduciría a reducirlo todo a problemas de hecho, a abandonar cualquier intento de configurar y comprender la historia. Cualquier proyecto de futuro debe contar con la utopía, de la misma manera que cuenta con lo sedimentado como una lección del pasado que no ha pasado por completo. Si dicho proyecto es utópico, no lo es por ser mera literatura de ficción, sino por su capacidad para distinguir lo dado de lo que podría ser, para no identificar lo real con lo racional como hace la conciencia feliz, y no caer en el inmovilismo. Una utopía no puede, sin embargo, realizarse de una vez por todas sin dejar de serlo, y ello no porque sea irrealizable, sino precisamente porque considera lo imposible como una posibilidad.

La combinación marcusiana de la descripción de la dominación y el esbozo de vías de liberación, esa particular relación entre fenomenología y marxismo, continúa siendo interesante en nuestra época y permite que el concepto histórico de "utopía" de Marcuse no sea arbitrario, pues debe probar ser más racional que la realidad establecida, debe ofrecer garan- 
tías de que mejorará la civilización, porque lo que esta sociedad denomina "utópico" es lo que en nuestra vida vemos como remedio contra la irracionalidad que pasa por racionalidad.

El deseo marcusiano de utopía, de una sociedad emancipada, es un tema constante que aún podemos hacer nuestro $\mathrm{y}$, sobre todo, que nos ayuda a comprender mejor los sutiles modos de dominio, sus grietas y los conatos de movimientos en contra. Marcuse es todavía un estímulo para la reflexión, quizás por su negativismo y su proyecto no planificado de revolución desde los individuos.

Cuando las instituciones políticas pierden legitimidad por la corrupción, por no velar por lo público y utilizarlo para fines privados, los individuos no solo no se sienten representados en ellas, sino desprotegidos. Quizás esta situación, favorece un criticismo como el marcusiano, una apelación a que la ciudadanía rechace los discursos que intentan convencerle de su impotencia ante el aparato y se movilice.

Somos conscientes, no obstante, de que hoy apenas se lee a Marcuse. Un ejemplo de ello es la interpretación literal de su "fin de la utopía". El título de su obra ha pasado a significar lo contrario de lo que verdaderamente designa, porque tendemos a apropiarnos de las consignas sin profundizar ni en el contexto ni en el concepto. Debido a ello, o bien juzgamos la utopía como una ingenuidad, o bien como un metarrelato peligroso. La utopía marcusiana, bien entendida, no es ninguna de ambas cosas: parte de una descripción rigurosa y radical de cómo estaban las cosas en la época -no demasiado alejada, por cierto, de la situación actual- y ofrece indicios para no perder la esperanza de la liberación. Ciertamente, la sutileza de los medios empleados para la integración en el sistema parece amenazarla, pero las muestras de solidaridad coexisten con el egoísmo incluso en una sociedad que se ha dado en llamar "líquida" por rendirse a la liquidez (Bauman). En sus últimos escritos, sin embargo, Marcuse sigue apelando a la solidaridad en base a la creación de nuevas necesidades y valores. En nuestro siglo XXI, Z. Bauman ha claudicado ante la ausencia de solidaridad. Está de acuerdo con el diagnóstico de Marcuse de la ideologización de la libertad en el mundo unidimensional, pero se muestra más pesimista que él, hasta el extremo de constatar la desaparición actual de la necesidad de libertad y autonomía $(2006,27)$ y, en consecuencia, desvincular la emancipación de la crítica. Desde nuestra perspectiva, Marcuse ya había comprobado la imposición de la pseudolibertad, tanto en las sociedades industriales avanzadas como en las soviéticas. Esta libertad - para el consumo- había sido introyectada por los individuos, que ya no sentían la necesidad de la liberación. La alternativa marcusiana va a la raíz del problema: a la concienciación en valores opuestos a los vigentes, a la orientación hacia necesidades pacificadoras y humanizadoras de la existencia. Tal vez no puedan definirse por el momento con más rigor, pero la crítica y la negación del orden establecido son la condición indispensable para desearlas.

Ya en Un Ensayo sobre la liberación, escrito antes del mayo del 68, aunque se publicara después, Marcuse aseguraba que:

Proclamando la "contestación permanente", la "educación permanente", "el Gran Rechazo", ellos reconocen el marco de la represión social $[. .$.$] han erigido de nuevo$ el fantasma $[\ldots]$ de una revolución que subordina el desarrollo de las fuerzas productivas y los altos estándares de vida a la exigencia de la solidaridad creadora con las especies humanas, con la abolición de la pobreza" (Marcuse, 1969, IX). 
En sus últimos escritos, el filósofo berlinés sigue apelando a la solidaridad en base a la creación de nuevas necesidades y valores. La emancipación pasa por esa solidaridad, que hoy se encarna en los movimientos por un crecimiento sostenible y en los decrecionistas.

Touraine (1925-) ha visto en esta reafirmación marcusiana de nuevos agentes sociales de la liberación un modo de superar la ruptura entre trabajo y vida que se ha producido en el siglo XXI. Ha sustituido el concepto de "clases sociales" por el de "movimientos sociales", que surgen ante conflictos colectivos; se trata de "conductas socialmente conflictivas, pero también culturalmente orientadas y no como la manifestación de contradicciones objetivas de un sistema de dominación" (Touraine, 2006, 258). Ambos reivindican al sujeto (individual y colectivo) frente al poder del mercado y atacan al neoliberalismo, que se rinde al poder de la mano invisible de este y renuncia al futuro.

La crítica marcusiana del liberalismo ataca su raíz: la racionalidad tecnológica (López Sáenz, 1988) que se ha impuesto sobre las subjetividades y hasta sobre los instintos como una nueva ideología. Es más, detecta una nueva ideología que deroga los conceptos decisivos de una sociedad libre calificándolos de "utópicos" cuando en ellos se encuentra "la diferencia decisiva" (Marcuse, 1969, 3-4) entre una sociedad auténticamente socialista y las sociedades establecidas, entre la praxis de las primeras y la tolerancia represiva o el laissez-faire liberal.

Como Goodwin asegura, la democracia liberal ejemplifica los defectos de una utopía realizada; se ha convertido en una ideología de dominio como vaticinaba Mannheim.

Pero muchos críticos contemporáneos aducen que el capitalismo liberal democrático avanzado es mucho más rígido, cerrado e intolerante que las utopías que condena: la crítica de Marcuse a la unidimensionalidad y a la tolerancia represiva constituye un ejemplo palmario de estas. La moraleja es que la realidad apoya la descripción de Mannheim de la transformación histórica de la utopía en ideología y su afirmación de la necesidad de un constante suministro de nuevas utopías (Goodwin, 1982, 114).

La denuncia de la hipocresía del liberalismo y su extensión al neoliberalismo es paralela a la defensa marcusiana de la liberación como exigencia de otra Razón y otra Libertad, que toma la forma de la Utopía para amparar su verdad (Marcuse, 2014, 98).

La globalización del mercado, las crisis ecológicas y otros tantos fenómenos actuales han reanudado la oposición al capitalismo voraz que todo lo convierte en medio, incluida la razón. Esta oposición revela que hay fisuras en la unidimensionalidad, que hay contradicciones y oposición que cristaliza en ciertos movimientos que aspiran a un cambio cualitativo del modo de vida. Esto sugiere que las categorías marcusianas continúan siendo útiles para analizar y contestar las formas de dominación, así como para crear focos de resistencia en el siglo XXI. Un ejemplo de ello es la utopía práctica de L. Davis, muy cercana a la marcusiana pues, en lugar de concebir la utopía como un "deber" opuesto al "ser" de la realidad política, la entiende "como una dinámica empíricamente fundada y como un rasgo abierto del 'mundo real', de la historia y la política que representa los deseos y sueños de los relegados a sus márgenes" (Davis, 2012, 127). Según el autor, la utopía actuaría en la interacción de los distintos momentos temporales. No estamos de acuerdo, sin embargo, con su separación entre las utopías trascendentes y las fundamentadas, pues la utopía práctica ha de ser ambas 
cosas; excluir su trascendencia es negarla como utopía y rendirse a la inmanencia del modo de producción y consumo capitalista que constituiría la distopía de la integración total, cuyo paradigma bien podría ser la "stark utopia" de K. Polanyi ${ }^{6}$ en la que los mercados se autorregulan de acuerdo con las preferencias de los individuos. Este modelo neoliberal destruiría la vida social, ya que tiende a producir un individualismo posesivo obviando las instituciones y las comunidades ¿Cómo las revitalizaremos? Cioran (1911-1995) diría que la utopía constituye un principio de renovación de las mismas. Nosotros apostamos por comprender con Marcuse que el dominio afecta a nuestros más profundos impulsos, porque, en realidad, lo privado es público y este es nuestro medio.

La dominación de la psicología profunda, denunciada por el berlinés, ha traído como consecuencia el hecho brutal de que casi la mitad de la población de los países desarrollados sufre alguna enfermedad mental, muchas veces sin diagnosticar. Otro vicio del capitalismo, de su Welfare State, es que siempre busca privatizar los beneficios y socializar los costes. Esto le lleva a legitimar que 24.000 personas mueran cada día de hambre en el mundo, siendo el $75 \%$ menores de 5 años, o que en la situación de crisis en la que vivimos en España, mientras uno de cada cinco hogares vive por debajo del umbral de la pobreza, las grandes fortunas y el consumo de bienes de lujo aumenten. He aquí nuevas versiones de la agudeza marcusiana para predecir la creciente coexistencia del desarrollo y del despilfarro, la subsistencia de la pobreza más extrema.

Siempre asociaremos a Marcuse con la preocupación por las posibilidades liberadoras de su concepto no-convencional de "utopía", con el criticismo que la antecede y la denuncia de que el sistema no la haga realidad. De la misma manera que él respondió con arrojo a la época convulsa que le tocó vivir, cuando lo leemos experimentamos su negativismo ante lo que vivimos reflexivamente en el siglo XXI, pero también su esperanza en la recuperación de una razón crítica que incorpore la sensibilidad, así como su apelación a la acción en un nuevo siglo superdesarrollado y comunicado en el que sigue habiendo guerras, totalitarismos y mucha infelicidad. Esta constatación, lejos de sumirnos en la desesperación, desarrolla nuestra empatía y proporciona contenido a nuestra coexistencia en el mundo convirtiéndola en una interacción consciente y en una llamada a la reflexión y al cambio que, aunque parezca demasiado local, contribuirá sin duda a incrementar la responsabilidad por las generaciones venideras, por el mundo y la cultura que recibirán como legado.

En caso de que la distopía fuera ganando terreno, siempre deberíamos lamentar el colapso del impulso utópico tal y como lo entendió Marcuse, es decir, el deseo de un cambio radical tras una crítica reflexiva de la existencia que trascienda la mera queja personal. Contra esta deriva, habla el hecho de que en 2015 hubo en Google 57,3 millones de sitios web sobre "utopía" (Capel, 2016, 17). Si la utopía fuera una pura fantasía, solo tendríamos un interés pasajero por ella, cuando lo cierto es que ha pasado a formar parte de nuestra historia e incluso del proclamado fin de la misma. Por ello, Fernández-Buey (1943-2012) asegura que, desde finales de los años 80, "utopía" se usa en sentido positivo para referirse a la esperanza de igualdad, como idea reguladora y horizonte sin el que no puede haber una realidad aceptable (Fernández-Buey, s.f.). En este sentido intencional y reflexivo, la utopía

6 The Great Transformation. Boston, Beacon Press, 1957. Cit. por Davis, 2012, 143. 
antropológica de Marcuse actúa orientando la praxis, proyectando nuevos valores en la vida, manteniendo vivo el principio de esperanza, recordándonos el poder de la imaginación y despertándonos a la realidad virtual que incluye en sí todo el universo del sentido.

La utopía marcusiana que hemos descrito en sus diferentes dimensiones, no es un escapismo, sino una dinámica teórica-práctica de crítica radical de lo existente para comprender todas sus potencialidades, especialmente las que han sido denigradas hasta extirparlas de nuestros deseos. Acercando a Marcuse a nuestra época desde la fenomenología en la que se formó, diríamos que la filosofía afincada en el mundo de la vida debe liberar y considerar todas las posibilidades de sentido y aceptar que urge un cambio cualitativo de las necesidades, no solo para que los hombres y mujeres de nuestra era no quieran repetir los totalitarismos que exterminaron todos los valores, sino sencillamente para que no quieran lo que quieren ahora, para que no crean que la política es eso que hacen los políticos. Si entendemos la política como búsqueda del sentido de la coexistencia, no tiene por qué oponerse a la utopía.

Resulta atractiva esta revitalización de la verdadera política, el antiautoritarismo marcusiano y su lucidez descriptiva y reflexiva, rasgos definitorios de la vida filosófica, de su criticismo y compromiso educativo y social cada vez más relegado por el sistema establecido.

\section{Referencias}

Bauman, Z. Tester, K. (2002), La ambivalencia de la Modernidad y otras conversaciones. Barcelona: Paidòs.

Bauman, Z. (2006), Modernidad líquida. México: FCE.

Bauman, Z. (2008), Archipiélago de excepciones. Buenos Aires: Katz.

Capel, H. (2016), "Las utopías pueden ayudar a construir el futuro", http://www.ub.edu/ geocrit/xiv_capeldiscurso.pdf

Cioran, E.M. (1960), Historia y utopía, http://crimideia.com.br/blog/wp-content/ uploads/2010/02/emil-cioran-historia-y-utopc3ada28196029.pdf

Cortina, A. (1986), Crítica y utopía, Madrid, Cincel.

Fernández-Buey, F. s.f. "La utopía frente al pensamiento utópico". http://www.cccb.org/ rcs_gene/fernndezbuey.pdf

Fernández-Buey, F. (2007-2008), ¿Es el decrecimiento una utopía realizable? Papeles de Relaciones Ecosociales y de Cambio Global, $\mathrm{n}^{\circ}$ 100, pp. 53-61.

Davis, L. (2012), "History, Politics and Utopia. Towards a Synthesis of Social Theory and Practice", en: Vieira, P. Marder, M. (eds.) Existential Utopia. New Perspectives on Utopian Thought, New York: Continuum International pp. 127-140.

Goodwin, B. (1982), The Politics of Utopia, New York: St. Martin's Press.

Habermas, J. (1983) [1971], Perfiles filosófico-políticos, Madrid: Taurus.

Habermas, J. (1984), "El fin de una utopía”, El País, 9/12/, http://www.uca.edu.sv/revistarealidad/archivo/4e1f052c76aa6elfindeunautopia.pdf pp. 535-545.

Habermas, J. (1986), Conversaciones con Herbert Marcuse. Barcelona: Gedisa.

Habermas, J. (2014), "Habermas Interviewed by M. Schwering. Internet and Public Sphere. What the Web Can't Do". http://www.resetdoc.org/story/00000022437. 24/7.

Jiménez, J. (1983), La estética como utopía antropológica. Bloch y Marcuse, Madrid: Tecnos. 
López Sáenz, Ma C. (1988) "La crítica de la racionalidad tecnológica en H. Marcuse", Enrahonar. Cuadernos de Filosofía, n 14, pp. 81-93.

López Sáenz, Mª C. (2000), El arte como racionalidad liberadora, Madrid: Uned.

López Sáenz, Ma C. (2006),"H. Marcuse: Trabajo y dolor como consecuencias de la represión”, en: González, M. (comp.) Filosofía y dolor, Madrid: Tecnos, pp. 439-454.

Mannheim, K. (1987) [1929], Ideología y utopía. Madrid: FCE.

Marcuse, H. (2011) [1929-1931], H. Marcuse. Entre hermenéutica y Teoría Crítica, Barcelona: Herder.

Marcuse, H. (1968³) [1934-8], Cultura y sociedad, Buenos Aires: Sur.

Marcuse, H. (19812) [1953], Eros y civilización, Barcelona: Ariel.

Marcuse, H. (1985a) [1955-60], Ensayo sobre política y cultura, Barcelona: Planeta.

Marcuse, H. (1985b) [1964], El hombre unidimensional, Barcelona: Planeta.

Marcuse, H. (1968) [1967], El final de la utopía, Barcelona: Ariel.

Marcuse, H. (1969), An essay on Liberation, Boston, Beacon Press.

Marcuse, H. (1998), Technology, War and Fascism. Collected Papers. One, London: Routledge.

Marcuse, H. (2001), Towards a Critical Theory of Society, Collected Papers. Two, London, Routledge.

Marcuse, H. (2005), The New Left and the 1960s. Collected Papers. Three, London: Routledge.

Marcuse, H. (2009), Negations. Essays in Critical Theory, London: MayFlyBooks.

Marcuse, H. (2014), Marxism, Revolution and Utopia. Collected Papers. Six, London, Routledge.

Panea, J.M. (1986), Querer la utopía. Razón y autoconservación en la Escuela de Frankfurt, Univ. De Sevilla.

Perlini, T. (1976), La Escuela de Frankfurt, Caracas: Monte Ávila.

Ricoeur, P. (1994) [1986], Ideología y utopía, Barcelona, Gedisa.

Touraine, A. (2006), "Los movimientos sociales", Revista Colombiana de Sociología, no 27 , pp. 255-278. 